\title{
SHARP INEQUALITIES FOR SOLUTIONS OF MULTIPOINT BOUNDARY VALUE PROBLEMS
}

\author{
PATRICIA J. Y. WONG
}

\begin{abstract}
This paper considers the following continuous and discrete multipoint boundary value problems: $x^{(n)}(t) \geqslant 0,0 \leqslant t \leqslant 1, x^{(j)}\left(t_{i}\right)=0$ and $\Delta^{n} y(k) \geqslant 0, k=0, \cdots, m, \Delta^{j} y\left(k_{i}\right)=0$, where $j=0, \cdots, n_{i}-1, i=1, \cdots, r, \sum_{i=1}^{r} n_{i}=n, 0=t_{1}<t_{2}<\cdots<t_{r}=1$, and $0=k_{1}<k_{1}+n_{1}<k_{2}<k_{2}+n_{2}<\cdots<k_{r} \leqslant k_{r}+n_{r}-1=m+n$. We offer lower bounds for solutions of these boundary value problems in terms of $\sup _{0 \leqslant t \leqslant 1}|x(t)|$ and $\max _{k \in\{0, \cdots, m+n\}}|y(k)|$. These bounds further lead to inequalities for related Green's functions which are very useful in the study of positive solutions of boundary value problems.
\end{abstract}

Mathematics subject classification (1991): 34A40, 39A10.

Key words and phrases: Continuous and discrete multipoint boundary value problems, differential and difference inequalities, Green's function.

\section{REFERENCES}

[1] R. P. Agarwal, Boundary Value Problems for Higher Order Differential Equations, World Scientific, Singapore, 1986.

[2] R. P. Agarwal, Difference Equations and Inequalities, Marcel Dekker, New York, 1992.

[3] R. P. AgARWAL AND P. J. Y. WONG, Error Inequalities in Polynomial Interpolation and their Applications, Kluwer, Dordrecht, 1993.

[4] R. P. Agarwal and P. J. Y. Wong, Advanced Topics in Difference Equations, Kluwer, Dordrecht, 1997.

[5] W. Coppel, Disconjugacy, Lecture Notes in Mathematics 220, Springer-Verlag, New York, 1971.

[6] P. W. EloE, A generalization of concavity for finite differences, In Advances in Difference Equations II, Computers Math. Appl. 36(10-12) (1998), 109-113.

[7] P. W. Eloe AND J. Henderson, Positive solutions for higher order ordinary differential equations, Electronic J. of Differential Equations 3 (1995), 1-8.

[8] P. W. Eloe and J. Henderson, Inequalities based on a generalization of concavity, Proc. Amer. Math. Soc. 125 (1997), 2103-2107.

[9] P. W. ElOE AND J. HENDERSON, Inequalities for solutions of multipoint boundary value problems, Rocky Mountain J. Math. (to appear).

[10] L. H. ERBE AND H. WANG, On the existence of positive solutions of ordinary differential equations, Proc. Amer. Math. Soc. 120 (1994), 743-748.

[11] P. HaRTMan, Difference equations: Disconjugacy, principal solutions, Green's functions, complete monotonicity, Trans. Amer. Math. Soc. 246 (1978), 1-30.

[11] P. J. Y. WONG, Positive solutions of difference equations with two-point right focal boundary conditions, J. Math. Anal. Appl. 224 (1998), 34-58.

[12] P. J. Y. WONG, Triple positive solutions of conjugate boundary value problems, Computers Math. Appl. 36(9) (1998), 19-35.

[13] P. J. Y. WONG AND R. P. AgaRwal, Double positive solutions of $(n, p)$ boundary value problems for higher order difference equations, Computers Math. Appl. 32(8) (1996), 1-21. 
[14] P. J. Y. Wong AND R. P. AgaRwal, Eigenvalue characterization for $(n, p)$ boundary value problems, J. Austral. Math. Soc. Ser. B 39 (1998), 386-407.

[15] P. J. Y. WONG AND R. P. AGARWAL, Extension of continuous and discrete inequalities due to Eloe and Henderson, Nonlinear Analysis 34 (1998), 479-487.

[16] P. J. Y. WONG AND R. P. AGARWAL, On the eigenvalues of boundary value problems for higher order difference equations, Rocky Mountain J. Math. 28 (1998), 767-791. 